\title{
DESCENTRALIZAÇÃO E PARTICIPAÇÃO SOCIAL: CONSTATAÇÕES E ANÁLISES COMPARATIVAS EM EXPERIÊNCIAS BRASILEIRAS DE DESCENTRALIZAÇÃO POLIITICO-ADMINISTRATIVA
}

\author{
DESCENTRALIZATION AND SOCIAL PARTICIPATION: \\ FINDINGS AND COMPARATIVE ANALYSIS ON BRAZILIAN \\ EXPERIENCIES OF POLITICAL AND ADMINISTRATIVE \\ DESCENTRALIZATION
}

\author{
Edson Luiz Cogo \\ Cogo Assessoria Jurídica e Advocacia - RS - Brasil \\ Valdir Roque Dallabrida \\ Universidade do Contestado - SC - Brasil
}

\begin{abstract}
Resumo: A descentralização da gestão pública no Brasil, oportunizada pelas diferentes experiências de descentralização político-administrativa, é tema atual e de profunda relevância para o avanço da democracia, haja vista os indicativos de participação social previstos na Constituição Federal Brasileira de 1988. Comparam-se as experiências de descentralização político-administrativa dos Estados de Santa Catarina (SC) e do Rio Grande do Sul (RS) e avalia-se a possibilidade de participação social na gestão pública, considerando o que está previsto nos marcos jurídicos em vigor. Pela análise, é possível afirmar que, mesmo que possam ser observados vícios na prática de ambas as experiências, o marco jurídico dos Conselhos Regionais de Desenvolvimento (RS) permite uma maior participação social. Contrariamente, nas Secretarias de Desenvolvimento Regional (SC), apesar de estar prevista a participação paritária entre o setor público e a sociedade civil na formação dos seus Conselhos, a indicação e nomeação dos integrantes é atribuição do Governo Municipal e Estadual, com o que fica comprometida a representatividade da participação da sociedade no processo.
\end{abstract}

Palavras-chave: Descentralização Político-Administrativa. Coredes (RS). Secretarias de Desenvolvimento Regional (SC). Participação Social.

Abstract: The descentralization of public management in Brazil oportunized by the different experiencies on political-administrative descentralization, is a nowadays issue with a deep relevance for the advancement of democracy, taking in to account the indicators of social participation under the 1988 Brazilian Federal Constitution. The experiences of descentralization in the fields of political and administrative are compared between the Rio Grande do Sul and Santa Catarina States. Also the possibility of social participation in the public management is assessed, under the legal framework in force. Considering the mentioned analysis it is possible to say that although some former error could occur, in both experiences, the Juridical Framework of the Development Regional Councils (RS) allows a major social participation. On the other hand the Regional Development Council (SC) despite being provided for the equally participation between the public sector and the civil society in the formation of their boards, the nomination and appointment of the members is a responsability of the State and the Cityhalls, with what is commited the representative participation of the society in the process.

Keywords: Political and Administrative Descentralization. COREDES(RS). Regional Development Councils(SC). Social Participation. 


\section{Introdução}

Retoma-se o estudo dos processos de descentralização ou desconcentração nos Estados de Santa Catarina (SC) e Rio Grande do Sul (RS). O objetivo aqui é avaliar como vem sendo oportunizada a participação social na experiência das Secretarias de Desenvolvimento Regional (SDRs) e dos Conselhos Regionais de Desenvolvimento (Coredes), respectivamente dos estados de SC e do RS, a partir da análise de seu marco jurídico ${ }^{1}$.

Tem-se como referencial teórico, a contribuição de autores que estudam a questão da descentralização, fortalecendo a sua autonomia e respeitando as vontades consubstanciadas no poder de decisão conferido à sociedade local (BOISIER, 2004; DALLABRIDA，2007/2011; BIRKNER，2006, MUÑOZ, 2007; FILIPPIM e ABRUCIO, 2010; ALLEBRANDT, 2010).

Conheceu-se, antes da Constituição Federal de 1988, formas de parcerias estabelecidas entre a sociedade civil e os governos, com vistas ao desenvolvimento regional. Por exemplo, a partir de 1960 surgiram as Associações de Municípios de Santa Catarina. No período pós-Constituição Federal de 1988, mecanismos jurídicos dispostos em seu texto passam a valorizar a perspectiva da descentralização. Assim, ressalta-se a importância do poder político local frente às decisões que sempre foram tomadas de cima para baixo, ou seja, do Estado para a sociedade, o que tem contribuído para a estruturação de experiências de descentralização político-administrativa. Nessa perspectiva, o estudo sustenta-se numa questão de investigação: quais as principais diferenças e semelhanças que podem ser encontradas no marco jurídico que regulamenta os processos de descentralização dos Estados de Santa Catarina e do Rio Grande do Sul, considerando as possibilidades de participação social?

Parte-se do entendimento de que a participação social nos processos de descentralização não ocorre automaticamente, sendo fundamental sua previsão no ordenamento jurídico. Assim, quando se faz referência aos resultados de uma ou outra experiência de descentralização político-administrativa, têm-se como hipótese que um processo será mais eficaz, sob o ponto de vista da prática da democracia, quanto maiores forem as possibilidades de divisão do poder estatal entre as representações sociais, políticas, institucionais e econômicas da sociedade atingida, devidamente previstas no marco jurídico.

Metodologicamente, optou-se pelo estudo comparativo da situação institucional de dois estados brasileiros, referente aos processos de descentralização político-administrativa intraestadual. Centrou-se a análise no marco jurídico, com as possíveis repercussões na sua prática organizativa e de funcionamento, a partir do que foi realizada a avaliação sobre as possibilidades de participação social. Para tal, foram consultados documentos oficiais onde constam as informações sobre o marco jurídico, focando as Secretarias de Desenvolvimento

\footnotetext{
1 Este texto resume estudos feitos quando da realização da dissertação (do primeiro autor) no Programa de Mestrado em Desenvolvimento Regional da Universidade do Contestado (sob a orientação do segundo autor).
} 
Regional (SDRs) e os Conselhos Regionais de Desenvolvimento (Coredes), respectivamente, dos estados de SC e do RS. Trata-se de um estudo exploratório, que merece aprofundamento a partir de outras variáveis.

\section{Descentralização, participação social e democracia}

No Brasil, a forma federativa de Estado foi adotada a partir da primeira Constituição Republicana de 1891. Por força do que dispõe o Artigo $1^{\circ}$ da Constituição Federal de 1988, o Brasil é um Estado federativo formado pela União, por Estados e Municípios, respeitando-se a autonomia de cada um desses entes federativos. É a Constituição Federal que estabelece as competências, sejam exclusivas ou concorrentes para tratar de determinados assuntos ou legislar sobre determinadas matérias (BRASIL, 1988).

Dallari (2005, p. 262) aponta como crítica ao estado federado, que “[...] na prática é impossível assegurar-se a todas as unidades federadas uma participação exatamente igual no exercício do poder político". A participação da sociedade no exercício do poder político é o que oportuniza a prática da democracia, entendida essa como a liberdade de exercício dos direitos civis e políticos dos cidadãos, vistos esses dentro da ótica dos direitos fundamentais. Nesse sentido, a Constituição Federal de 1988 oportunizou a criação de mecanismos que conferem poderes à participação social e ao fortalecimento das forças democráticas, propondo diferentes formas de descentralização da gestão das coisas públicas.

\subsection{Participação social na gestão pública}

A Constituição Federal de 1988 traz em seu preâmbulo a instituição de um Estado Democrático de Direito, reforçando os valores nacionais em busca da garantia do exercício dos direitos sociais e individuais, liberdade e igualdade, o bem-estar e a segurança de uma sociedade fraterna, pluralista e sem preconceitos, fundada na harmonia social. Por esse entendimento, o Artigo $1 .{ }^{\circ}$ prevê que " [...] todo o poder emana do povo, que o exerce por meio de representantes eleitos ou diretamente" (BRASIL, 1988). Assim sendo, a nova Constituição trouxe em seu texto a possibilidade de repartir com a sociedade civil organizada a gestão das coisas públicas, permitindo a criação de diversos Conselhos com tais fins.

Num país em que vigorou um longo período de exceção, de 1964 a 1985, não se pode negar que, com a Constituição de 1988, houve consideráveis avanços no processo democrático, com abertura de espaços aos cidadãos para que exerçam sua participação de forma aberta e democrática, mesmo que, como assevera Dowbor (2008), esses mecanismos nos países em desenvolvimento sejam ainda relativamente frágeis. O mesmo autor ressalta: "A participação comunitária constitui hoje claramente o mecanismo mais racional de regulação das principais atividades da área social, da urbanização, da pequena e média produção, além de constituir um 'lastro' indispensável para o equilíbrio do conjunto das atividades em nível macroeconômico" (DOWBOR, 2008, p. 56). 


\subsection{A descentralização político-administrativa: desconcentração e descentralização}

As diferentes formas de descentralização constituem-se numa iniciativa do Estado, garantindo aos cidadãos os direitos fundamentais de participação na gestão pública assegurados na Constituição Federal.

Durante a década de 1980, no Brasil, os movimentos sociais passaram a reclamar formas efetivas de descentralização político-administrativa. A Constituição Federal de 1988 contemplou o tema no artigo 43, indicando a criação de políticas públicas para o desenvolvimento, atribuindo à própria sociedade civil a oportunidade de participar na gestão pública dentro de determinados assuntos. Assim, a descentralização seria uma diretriz a ser assumida por todos os entes da federação (União, Estados e Municípios), a fim de deslocar competências, antes exclusivas do Estado centralizado, para as mãos dos cidadãos brasileiros.

O termo descentralização, geralmente, é utilizado para referir-se à transferência de atribuições do Estado à iniciativa privada, à concessão de serviços públicos ou transferência de poder do governo para uma comunidade ou para uma ONG (ABRUCIO, 2006). Medici (1994) ainda menciona ser uma forma de descentralização a transferência da administração ou à execução de políticas sociais pela administração direta para a administração indireta, como autarquias, fundações, empresas públicas ou de economia mista, como formas de descentralização. Já a desconcentração assume um sentido específico, diferenciado. Afirma Medauar (2003, p. 56-57): "Existe a desconcentração quando as atividades são distribuídas de um centro para setores periféricos ou de escalões superiores para escalões inferiores, dentro da mesma entidade ou mesma pessoa jurídica".

Pelos princípios democráticos, espera-se que o Estado permita às regiões a possibilidade de gerir o seu próprio destino, delegando poderes às instituições locais com intuito de fortalecimento do poder local e visando à melhoria das condições de vida da sua população. Esclarece, no entanto, Dawbor (2008, p. 40) que "[...] não se trata de inverter os processos substituindo o poder central pelo poder local, mas de equilibrar os diversos níveis do processo decisório".

Com base na diretriz constitucional nacional, ao estimular diferentes formas de descentralização, possibilitando a ampla participação dos atores sociais, em nome de avanços na democracia, as constituições dos estados federados também fizeram previsões nesse sentido, como ocorreu, por exemplo, nos Estados de Santa Catarina e do Rio Grande do Sul, a partir de 1989, que será visto no decorrer deste artigo.

\section{O marco jurídico do processo de descentralização político-administrativa no estado de Santa Catarina}

O Estado de Santa Catarina é caracterizado por ser o menor dos estados da região sul do Brasil, sendo composto por 293 municípios e uma população de 6.249.682 pessoas (BRASIL-IBGE, 2010). 
A Constituição Estadual de Santa Catarina, promulgada em 05 de outubro de 1989 (SANTA CATARINA, 1989), faz referência, em capítulos específicos, aos assuntos municipais e microrregionais (artigos 110 a 114) e também conta com um capítulo dedicado ao desenvolvimento regional e urbano (artigos 138 a 143), bem como contempla o tema do desenvolvimento rural (artigos 144 a 148). O marco jurídico do processo de descentralização atual, e que é objeto deste artigo, ocorreu em 2003, com a promulgação da Lei Complementar n. 243 (SANTA CATARINA, 2003), que estabeleceu a nova estrutura administrativa no Estado de Santa Catarina. Conforme seu artigo 9. ${ }^{\circ}$, o enfoque era a descentralização das atividades e funções das Secretarias de Estado Centrais para as Secretarias de Desenvolvimento Regional. Com esse ato foram criadas 29 Secretarias de Estado de Desenvolvimento Regional, sendo criadas, a posteriori, mais sete secretarias, perfazendo atualmente um total de 36 secretarias.

Da metade da década de 1990 até 2002, existiam, nas regiões do estado de Santa Catarina, os Fóruns Regionais de Desenvolvimento, articulados pelas Associações de Municípios e que desempenhavam a função de fóruns de discussão e articulação de estratégias de desenvolvimento regional, podendo ser considerados estruturas embrionárias de descentralização da gestão pública, com participação de representações do Estado, municípios, instituições regionais e representações sociais e corporativas².

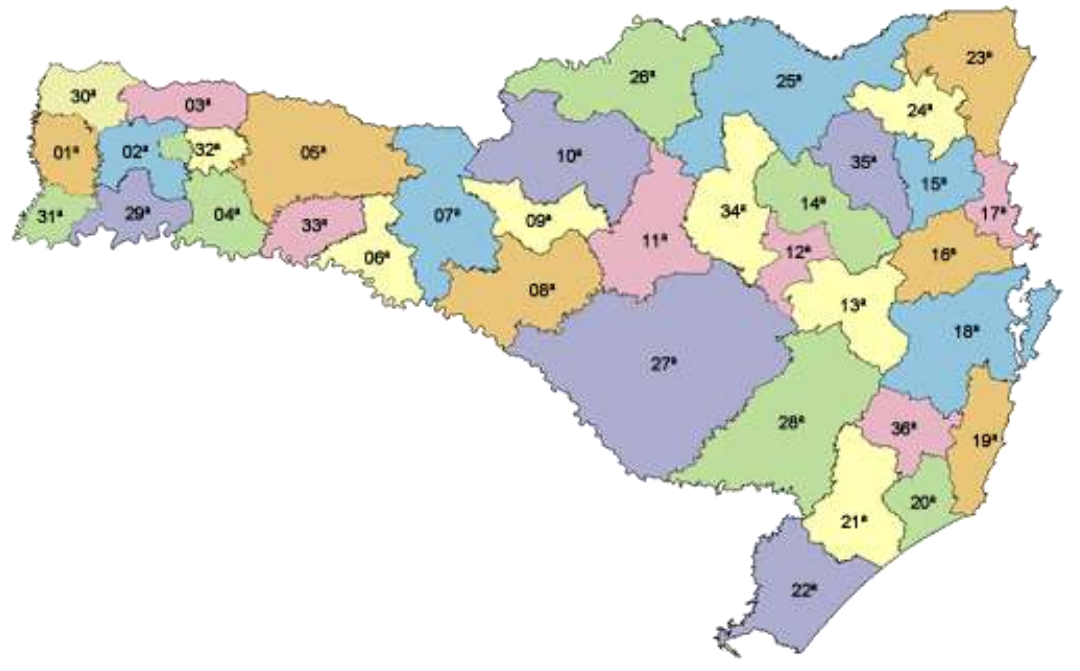

Mapa 1. Mapa do Estado de Santa Catarina - SDRs das 36 regiões

\begin{tabular}{|l|l|}
\hline $01^{\mathrm{a}}-$ São Miguel D'Oeste & $19^{\mathrm{a}}-$ Laguna \\
\hline $02^{\mathrm{a}}-$ Maravilha & $20^{\mathrm{a}}-$ Tubarão \\
\hline $03^{\mathrm{a}}-$ São Lourenço do Oeste & $21^{\mathrm{a}}-$ Criciúma \\
\hline $04^{\mathrm{a}}-$ Chapecó & $22^{\mathrm{a}}-$ Araranguá \\
\hline $05^{\mathrm{a}}-$ Xanxerê & $23^{\mathrm{a}}-$ Joinville \\
\hline $06^{\mathrm{a}}-$ Concórdia & $24^{\mathrm{a}}-$ Jaraguá do Sul \\
\hline $07^{\mathrm{a}}-$ Joaçaba & $25^{\mathrm{a}}-$ Mafra \\
\hline $08^{\mathrm{a}}-$ Campos Novos & $26^{\mathrm{a}}-$ Canoinhas \\
\hline
\end{tabular}

\footnotetext{
${ }^{2}$ Tais institucionalidades não serão objeto de analise neste artigo. Ver abordagem sobre o tema em: Birkner (2006); Theis et al. (2011). Em Dallabrida (2011), vários capítulos analisam tanto a experiência catarinense de descentralização, como a do Rio Grande do Sul.
} 


\begin{tabular}{|l|l|}
\hline $09^{\mathrm{a}}-$ Videira & $27^{\mathrm{a}}-$ Lages \\
\hline $10^{\mathrm{a}}-$ Caçador & $28^{\mathrm{a}}-$ São Joaquim \\
\hline $11^{\mathrm{a}}-$ Curitibanos & $29^{\mathrm{a}}-$ Palmitos \\
\hline $12^{\mathrm{a}}-$ Rio do Sul & $30^{\mathrm{a}}-$ Dionísio Cerqueira \\
\hline $13^{\mathrm{a}}-$ Ituporanga & $31^{\mathrm{a}}-$ Itapiranga \\
\hline $14^{\mathrm{a}}-$ Ibirama & $32^{\mathrm{a}}-$ Quilombo \\
\hline $15^{\mathrm{a}}-$ Blumenau & $33^{\mathrm{a}}-$ Seara \\
\hline $16^{\mathrm{a}}-$ Brusque & $34^{\mathrm{a}}-$ Taió \\
\hline $17^{\mathrm{a}}-$ Itajaí & $35^{\mathrm{a}}-$ Timbó \\
\hline $18^{\mathrm{a}}-$ Grande Florianópolis & $36^{\mathrm{a}}-$ Braço do Norte \\
\hline
\end{tabular}

Fonte: https://www.mp.sc.gov.br

Em 2005, a Lei Complementar n. 243 foi revogada pelo artigo 217 da Lei Complementar n. ${ }^{\circ}$ 284, (SANTA CATARINA, 2005), a qual estabeleceu o modelo de gestão para a Administração Pública Estadual e dispôs sobre a estrutura organizacional do Poder Executivo e reforma administrativa. Com essa lei passaram a existir 30 Secretarias. Em 2007, houve nova alteração legislativa no estado de Santa Catarina, por meio da Lei Complementar n. ${ }^{\circ} 381 / 2007$, chamada Lei da Reforma Administrativa, que dispôs sobre o modelo de gestão e a estrutura organizacional da Administração Pública Estadual, secretaria executiva e gestão de fundos estaduais. Tal legislação inicia enfatizando a necessidade de que a estrutura organizacional administrativa deverá "[...] desburocratizar, descentralizar e desconcentrar os circuitos de decisão" (SANTA CATARINA, 2007). Ainda de acordo com a mesma legislação, as Secretarias de Desenvolvimento Regional, que atuam de forma articulada com as Secretarias Setoriais (Artigo 13 e 55), têm entre suas funções atuar como agências de desenvolvimento regional na forma especificada no $\S 1 .^{\circ}$, do Artigo $2 .^{\circ}$, desta legislação (SANTA CATARINA, 2007).

As Secretarias de Desenvolvimento Regional limitadas em 36, conforme a Lei Complementar 381/2007, têm como seu órgão colegiado o Conselho de Desenvolvimento Regional, que assim é constituído:

\section{I - membros natos:}

a) o Secretário de Estado de Desenvolvimento Regional;

b) os Prefeitos da região de abrangência; e

c) os Presidentes das Câmaras de Vereadores da região de abrangência; e

II - dois representantes, por município da região de abrangência, membros da sociedade civil organizada, assegurando-se a representatividade dos segmentos culturais, políticos, ambientais, econômicos e sociais mais expressivos da região, definidos por decreto do Chefe do Poder Executivo.

Os Conselhos de Desenvolvimento Regional são órgãos de apoio, auxílio, aconselhamento, incentivo de programas, emissão de pareceres, entre outros, definidos pelo Artigo 83 da Lei Complementar 381/2007. Esses Conselhos têm seu Regimento Interno aprovado por decreto do Chefe do Poder Executivo Estadual. 


\section{O marco jurídico do processo de descentralização político-administrativa no estado do Rio Grande do Sul}

O Rio Grande do Sul é composto por 496 municípios, contando atualmente com uma população de 10.695 .532 pessoas (BRASIL-IBGE, 2010).

A Constituição Estadual do Rio Grande do Sul contempla artigos que se constituem no marco jurídico para a implementação de políticas públicas de desenvolvimento e que atualmente dão sustento jurídico aos Coredes. É o caso dos artigos 8 a 16 que tratam especificamente do Município e os artigos 16 à 18 que preveem acerca da região metropolitana, das aglomerações urbanas e das microrregiões, e ainda os artigos 166 e 170, que tratam especificamente das políticas do desenvolvimento estadual e regional (RIO GRANDE DO SUL, 1989).

O marco jurídico da descentralização no estado do Rio Grande do Sul é a Lei 10.283/94 que foi regulamentada pelo Decreto 37.764/94. No momento da promulgação dessa norma, havia 21 Coredes. Desde janeiro de 2008, com a edição do Decreto n. ${ }^{\circ}$ 45.436, foram criadas as últimas regiões, passando atualmente para 28 regiões dos Coredes (RIO GRANDE DO SUL, 1994a; 1994b).

Os objetivos e as atribuições dos Coredes estão previstos nos artigos $2 .^{\circ} \mathrm{e}$ 3. ${ }^{\circ}$ da Lei 10.283/94.

Art. $2^{\circ}$ - Os Conselhos Regionais de Desenvolvimento têm por objetivo a promoção do desenvolvimento regional, harmônico e sustentável, através da integração dos recursos e das ações de governo na região, visando à melhoria da qualidade de vida da população, à distribuição equitativa da riqueza produzida, ao estímulo à permanência do homem em sua região e à preservação e recuperação do meio ambiente.

Art. $3^{\circ}$ - Compete aos Conselhos Regionais de Desenvolvimento, dentre outras, as seguintes atribuições:

I - promover a participação de todos os segmentos da sociedade regional no diagnóstico de suas necessidades e potencialidades, para a formulação e implementação das políticas de desenvolvimento integrado da região;

II - elaborar os planos estratégicos de desenvolvimento regional;

III - manter espaço permanente de participação democrática, resgatando a cidadania, através da valorização da ação política;

IV - constituir-se em instância de regionalização do orçamento do Estado, conforme estabelece o artigo 149, parágrafo $8^{\circ}$ da Constituição do Estado;

$\mathrm{V}$ - orientar e acompanhar, de forma sistemática, o desempenho das ações dos Governos Estadual e Federal na região;

VI - respaldar as ações do Governo do Estado na busca de maior participação nas decisões nacionais.

O artigo $4 .^{\circ}$ da Lei n. ${ }^{\circ} 10.283 / 94$ destaca a sua estrutura organizacional, fazendo referência à constituição da Assembleia Geral dos Conselhos, a instância na qual é oportunizada a participação da sociedade nas decisões sobre desenvolvimento regional, a ser composta pelos prefeitos municipais, presidente das câmaras de vereadores, deputados estaduais e federais com domicílio eleitoral na região, representantes das instituições de ensino superior e um representante de cada segmento da sociedade civil organizada, nestes termos: 
Art. 4. ${ }^{\circ}$ A Assembleia Geral Regional, órgão máximo de deliberação do Conselho Regional de Desenvolvimento - COREDE, terá a seguinte composição:

I - os prefeitos municipais e os presidentes das Câmaras de Vereadores da região, como membros natos;

II - os deputados estaduais e federais com domicílio eleitoral na região, como membros natos;

III - um representante de cada instituição de ensino superior da região, com mandato de dois anos, permitida uma recondução;

IV - um representante, e respectivo suplente, por município da região, de cada segmento organizado da sociedade civil, tais como associações, sindicatos, fundações, clubes de serviço e conselhos setoriais instituídos por lei, com mandato de dois anos, permitida uma recondução.

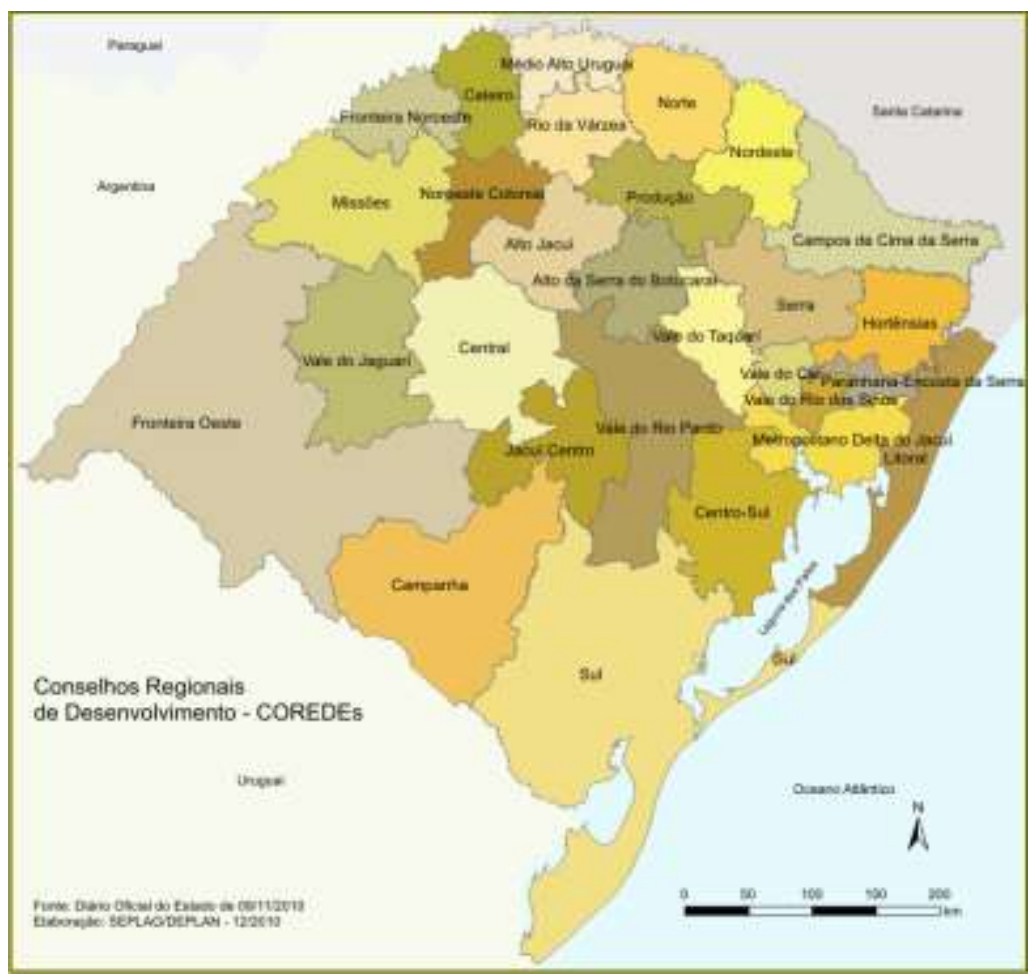

Mapa 2. Mapa do Rio Grande do Sul e as 28 regiões dos Coredes

Fonte: Rio Grande do Sul. Diário Oficial do Estado (2010)

O parágrafo único do artigo $4 .^{\circ}$ permitiu que cada Corede formulasse seus Estatutos e Regimentos Internos ao dispor: "Cada Conselho Regional de Desenvolvimento elaborará o seu Regimento Interno, estabelecendo sua composição, formas de deliberação, representação e participação, observadas as normas desta Lei". Para ilustrar, ao examinarem-se os Estatutos de alguns Coredes como o da região Central, Rio da Várzea e Corede Sul, verifica-se que há pouquíssimas variações na previsão da questão da representatividade. Exemplificativamente, veja-se o que diz o Estatuto do Corede Central sobre o assunto: 
Art. $12^{\circ}$ - Fica estabelecido que os Conselhos serão eleitos pela Assembleia Geral Regional, através dos seguintes critérios:

I- Membros Natos:

a) Os Deputados Federais com domicílio eleitoral na região;

b) Os Deputados Estaduais com domicílio eleitoral na região;

c) Os Prefeitos dos Municípios pertencentes à Região Central;

d) Um representante de cada Câmara Municipal de Vereadores dos Municípios pertencentes à Região Central, indicados pelos Legisladores Municipais.

II- Os escolhidos por entidades representativas:

a) Um representante dos Trabalhadores Rurais;

b) Um representante dos Trabalhadores na Indústria;

c) Um representante dos Trabalhadores do Setor de Comércio e Serviços;

d) Um representante dos Empresários do Setor Rural;

e) Um representante dos Empresários do Setor Industrial;

f) Um representante dos Empresários do Setor de Comércio e Serviços;

g) Um representante do Conselho de Desenvolvimento Municipal escolhido pelos Conselhos legalmente constituídos na região;

h) Um representante dos Conselhos Municipais de Saúde, Educação, da Criança e do Adolescente, Conselho Municipal de Assistência Social e do idoso;

i) Um representante das Associações Comunitárias, escolhido pelas Associações legalmente constituídas na região;

j) Um representante das Cooperativas, escolhidos pelas Cooperativas da região;

k) Um representante dos movimentos ecológicos, escolhidos pelas entidades ecológicas legalmente constituídas na região;

l) Um representante do Funcionalismo Público, escolhido pelos funcionários públicos da região;

m) Um representante de cada Instituição de Ensino Superior da região;

n) Três representantes dos demais segmentos organizados da sociedade civil (Clubes de Serviço, Entidades Religiosas, Entidades Assistenciais, Profissionais Liberais, Entidades Culturais e Entidades de Defesa da Cidadania);

o) Um representante dos estudantes secundaristas, escolhidos através dos Grêmios Estudantis;

p) Um representante dos estudantes universitários, escolhido através dos Diretórios Acadêmicos;

q) Um membro nato por município escolhido por entidades organizadas do referido município.

Parágrafo Primeiro - As entidades indicarão seus representantes e, em igual número, os seus respectivos suplentes.

Parágrafo Segundo - Os suplentes dos membros da Assembleia Geral ocuparão igual suplência na composição do Conselho.

Em geral, os Regimentos Internos dos Coredes das demais regiões se assemelham, diferindo apenas em aspectos secundários.

Em 28 de março de 2000 foi promulgada a Lei n. 11.451 que, acrescendo artigos à Lei dos Coredes, criou os Conselhos Municipais de Desenvolvimento (Comudes). Os Comudes foram criados para complementar e auxiliar a ação dos Coredes e com o objetivo de promover o desenvolvimento de ações do poder público com organizações privadas, entidades da sociedade civil e cidadãos, com o 
intuito de melhorar a qualidade de vida da população (SAAD e SIEDENBERG, 2007).

\section{Análise do marco jurídico catarinense}

Atualmente são 36 as Secretarias de Desenvolvimento Regional (SDRs) no Estado de SC. Para cada uma dessas foi criado um cargo, com status de Secretário de Estado. Os Secretários são vinculados ao mesmo partido político do Governador do Estado ou à coligação eleitoral que o elegeu. Além disso, em geral, os trabalhadores desses órgãos são servidores públicos de carreira. Foram ainda criados cargos em comissão (de livre nomeação e livre exoneração por seus superiores), sem a necessidade de prestar concurso público. Segundo Filippim e Abrucio (2010), os detentores dos cargos comissionados existentes nas SDRs, indicados pelos partidos que compõem a base governista podem ser vistos como verdadeiros cabos eleitorais.

Os Regimentos Internos das SDRs são aprovados por Decreto do Governador do Estado. Isso quer dizer que as Secretarias de Desenvolvimento têm sua autonomia restrita, pois tudo que decidem e sugerem deve passar pela análise do Governador do Estado ou por sua assessoria jurídica. Sua estrutura organizacional e de funcionamento é definida por leis, que devem ser observadas, tanto pelo servidor público, como pelas representações sociais e políticas que as compõem.

Os Conselhos de Desenvolvimento Regional no Estado de Santa Catarina, segundo a Lei Complementar 285/05, regulamentados pelo Decreto 2.639/09 prevê os seguintes órgãos em sua estrutura funcional: Assembleia Geral, Secretaria Executiva e Comitês Temáticos. As SDRs preveem a seguinte forma de representação: como membros natos, o Secretário de Desenvolvimento Regional, os Prefeitos Municipais e os Presidentes de Câmaras de Vereadores de cada município da região de abrangência; os demais membros serão dois representantes da sociedade civil organizada, por município, com direito a voto, assegurando-se a representatividade dos segmentos culturais, políticos, ambientais, econômicos e sociais mais expressivos da região, instituídos no cargo pelo Chefe do Poder Executivo, conforme Decreto 2.639/09.

A interferência do Executivo Estadual dentro das Secretarias é facilmente perceptível, pois o simples ato de aprovação dos regimentos internos depende da aprovação do Chefe do Executivo Estadual como pode ser verificado através da lei específica (SANTA CATARINA, 2009a; 2009b; 2009c; 2009d), podendo o Executivo vetar matérias e decisões tomadas nas SDRs.

Por outro lado, o Decreto 2.639/09, que legisla sobre o Regimento Interno dos Conselhos das SDRs, define que as reuniões devem ser realizadas em locais que ofereçam maior capacidade de público de modo a ampliar a participação popular e incentivar a inclusão política do cidadão. Muito embora haja esta previsão no Regimento Interno, a chamada participação popular como forma de inclusão política do cidadão, não tem por consequência dar-lhe voz, pois não passa 
de um mero ouvinte das decisões que são tomadas pelo Conselho, como pode ser verificado pelo artigo 28 do referido decreto estadual, prevendo que as votações serão abertas e nominais e cada conselheiro manifestará seu voto de forma clara e verbal. Fica bem claro: só votam os conselheiros que estão devidamente indicados pelo Chefe do Poder Executivo Estadual. Portanto, não existe a menor possibilidade de participação direta no processo decisivo àqueles cidadãos que comparecem às reuniões do Conselho.

Com relação à representatividade da sociedade civil nos Conselhos, à guisa de amostragem, foram analisados os decretos que nomearam os conselheiros das SDRs de Blumenau e de Jaraguá do Sul ${ }^{3}$. Todas essas legislações dispõem sobre a composição de membros natos, representantes da sociedade civil organizada e participação de órgãos e entidades da Administração Direta e Indireta no Conselho de Desenvolvimento Regional. Os representantes da sociedade civil organizada no Conselho de Desenvolvimento Regional de Blumenau são: do município de Blumenau, a Fundação Universidade Regional de Blumenau e a Associação Comercial e Industrial de Blumenau; de Gaspar, a Associação Comercial e Industrial de Gaspar e Sindicato de Trabalhadores; de Ilhota, o Sindicato Rural e a Associação Beneficente Cristã; em Luís Alves, a Associação dos Bananicultores de Luís Alves e a Federação dos Trabalhadores na Agricultura do Estado de Santa Catarina; em Pomerode, a sociedade civil está representada pelo Sindicato das Empresas de Serviços Contábeis, Assessoramento, Perícias, Informações e Pesquisas no Estado de Santa Catarina e a Associação Comercial e Industrial de Pomerode.

Já no Conselho de Desenvolvimento Regional da região de Jaraguá do Sul, composta por cinco municípios, a sociedade civil organizada está assim representada: em Jaraguá do Sul, pelo Centro Universitário de Jaraguá do Sul e a Associação Comercial e Industrial de Jaraguá do Sul; em Corupá, pelo Sindicato de Trabalhadores Rurais e Associação Empresarial de Corupá; em Guaramirim pela Faculdade Metropolitana de Guaramirim e Associação Comercial Industrial e Agropecuária de Guaramirim; em Schroeder, pela Federação das Associações de Produtores de Banana de Santa Catarina e Associação Comercial e Industrial de Schroeder; em Massaranduba, pelo Rotary Club e Associação Empresarial.

Pelo que se observa acerca da representação da sociedade civil no processo de descentralização do Estado de Santa Catarina, utilizando os exemplos referidos, pode-se dizer: primeiro, que é definida conforme o crivo pessoal do Chefe do Poder Executivo Estadual; segundo, que contempla, como segmentos da sociedade civil organizada, entidades civis ou corporativas, ou pessoas que ocupam um cargo destacado perante a sociedade, majoritariamente do setor empresarial ou representantes de órgãos públicos, o que restringe a participação social, especialmente dos segmentos populares, no processo decisório. Assim, os demais representantes da sociedade são alijados do processo decisório, podendo-se afirmar que é restrita a participação social, segundo o que prevê a legislação catarinense, apesar da publicidade feita nas publicações oficiais do governo.

\footnotetext{
${ }^{3}$ Dados referentes à situação de 2011.
} 
Como pontos positivos a serem destacados nesse marco jurídico objeto de análise, podem ser destacados a organização e o funcionamento das SDRs, que contam com o aparato estatal para o seu pleno funcionamento, com toda uma estrutura colocada à disposição da sociedade. Outro fato positivo e que chama a atenção, com relação aos problemas e às necessidades locais e regionais, são os diagnósticos e as informações coletadas pelas SDRs, além da presença física de estruturas administrativas do Estado desconcentradas nas regiões, próximas à população.

\section{Análise do marco jurídico do RS}

A experiência gaúcha de descentralização político-administrativa já completou mais de vinte anos de existência, sendo que seu marco jurídico, a Lei 10.283/94, regulamentada pelo Decreto 35.764/94, permanece o mesmo, com pequenas alterações introduzidas em seu texto legal. Os Coredes exercem suas atividades com plena autonomia em relação ao governo estadual. Sua composição, segundo a lei que os criou, está assim definida: os Prefeitos Municipais e os Presidentes das Câmaras de Vereadores, como representantes dos poderes públicos da região; os Deputados Estaduais e Federais com domicílio eleitoral na região; um representante de cada instituição de ensino superior da região; e, um delegado com seu suplente, como representante eleito pelos seus pares de cada segmento organizado da sociedade civil de cada Município da região.

A legislação dos Coredes permite que a instituição elabore seu Regimento Interno e Estatutos e estabeleça sua composição, formas de deliberação, representação e participação. Tudo isso depois é submetido à Assembleia Geral Regional que é a instância que chancela a aprovação do Estatuto. Por serem considerados pessoas jurídicas de direito privado, os Coredes são organizados sob a forma de associações civis sem fins lucrativos, sem qualquer intervenção do Poder Executivo. Como pessoas jurídicas de direito privados que são, o único requisito para validar os seus estatutos é o registro formal no respectivo cartório de títulos e documentos, quando, então, passam a ter valor legal. A Assembleia Geral Regional dos Coredes, pela representação prevista em seus estatutos, elege o Presidente que o representará no âmbito estadual e perante o Fórum dos Coredes, seu órgão máximo.

Diante desse quadro, pode-se fazer a seguinte comparação: as SDRs são pessoas jurídicas de direito público, vinculadas ao Estado, seu Regimento Interno é aprovado por Decreto do Chefe do Poder Executivo estadual, enquanto os Coredes são pessoas jurídicas de direito privado, sob a forma de associações civis, sendo seus Regimentos Internos elaborados por cada um dos Conselhos Regionais, bastando para sua aprovação a deliberação da Assembleia Geral Regional.

Como membros natos aparecem os Prefeitos Municipais, os Presidentes das Câmaras de Vereadores e os Deputados Estaduais e Federais com domicílio eleitoral na região. Destaca-se, no entanto, a representação das instituições de ensino superior da região, bem como a presença de um delegado como 
representante de cada segmento organizado da sociedade civil. Fica evidente aqui a abertura da legislação para que pessoas representantes das comunidades, das instituições de ensino superior e membros da sociedade civil organizada participem do processo de tomada de decisão. Além de permitir uma ampla participação social nos Conselhos Regionais de Desenvolvimento, destaca-se também a criação dos Conselhos Municipais de Desenvolvimento, os Comudes, criados por Lei Estadual no ano 2000.

Com relação ao custeio das atividades dos Coredes, o artigo 10 da Lei 10.283/94 prevê dotação específica no Orçamento do Estado para a manutenção das atividades dos Coredes. Por serem pessoas jurídicas de direito privado não há servidores públicos lotados nos Coredes e, por absoluta vedação legal, não é permitida nenhuma espécie de remuneração aos seus membros, por ser a atuação nos Coredes considerada função pública relevante.

Ponto negativo que se observa na análise dos Coredes é a sua relação com os governos estaduais. Pelo exposto por Allebrandt (2010) e Muñoz (2007), chega-se à conclusão de que os governos estaduais do RS disputam o espaço público conquistado pelos Coredes e, principalmente, pela formação das suas bases. Segundo tais autores, esses conflitos, mesmo que ocasionais, têm contribuído para afastar as partes envolvidas do foco sobre questões cruciais referentes às políticas de desenvolvimento regional. Outro fato que merece ser destacado é que pela história política do Rio Grande do Sul, nunca houve reeleição para o cargo de Governador do Estado $^{4}$, com o que nenhum dos então governadores estaduais conseguiu permanecer no poder por mais de um mandato. Mesmo com as restrições em relação à sua prática, com os Coredes têm-se no Rio Grande do Sul os mecanismos legais para que se possa estabelecer uma governança territorial democrática e participativa. Isso não significa dizer que esses órgãos conseguem efetivamente concretizar, na sua plenitude, a participação social. Considera-se que são necessários avanços.

A matéria do debate ainda se apresenta como uma questão não conclusiva. Avanços nos dois estados resultarão do amadurecimento de experiências vivenciadas pela sociedade, tendo uma forte relação com o estágio de avanço democrático.

\section{Considerações finais}

Quando se fala em descentralização de poder, explicitamente fala-se em democracia e poder compartilhado na gestão pública e para isso se faz necessária a participação da sociedade civil organizada. Na experiência de descentralização de Santa Catarina é o próprio Chefe do Poder Executivo Estadual quem, em última instância, delibera acerca dos nomes daqueles que são indicados para representar a sociedade civil nos Conselhos de Desenvolvimento Regional. Além disso, é notória a presença majoritária de empresários como representantes da sociedade civil, o que revela ausência de representação paritária entre as diferentes classes sociais.

\footnotetext{
${ }^{4}$ Isso, ao menos, de 1988 até 2014.
} 
Analisando a experiência gaúcha, percebe-se que a história registra conflitos entre os Coredes e governos de diferentes siglas partidárias, preferindo relacionarse com esses apenas através de uma política de boa vizinhança, sem dar-lhes o merecido destaque. O motivo talvez seja o fato de os Coredes terem a liberdade de agir autonomamente.

$\mathrm{Na}$ análise dos marcos jurídicos do processo de descentralização dos dois estados, no que diz respeito à possibilidade de participação social, ficou evidente que a legislação catarinense é restritiva quanto à participação dos representantes da sociedade civil organizada na gestão das coisas públicas. Já a legislação gaúcha é mais aberta à inclusão dos diferentes grupos sociais, pois permite a inserção dos mesmos, com representação paritária, evitando formas de seletividade ou exclusão.

Muito embora ainda seja cedo para avaliar o desempenho dessas legislações, uma coisa é certa: não há uma efetiva descentralização do poder, principalmente, nas SDRs. Na verdade, o que há é uma forma de desconcentração político-administrativa em Santa Catarina, quando o Poder Executivo central instala as Secretarias de Desenvolvimento Regional, as quais articulam nas regiões a implementação de políticas públicas voltadas ao desenvolvimento regional. Pode-se, então, afirmar que não há autonomia administrativa nem financeira nesses órgãos regionais e também não há uma efetiva participação da sociedade civil organizada.

No entanto, em que pesem as falhas e dificuldades encontradas ao longo do caminho, a história dos Coredes se aproxima mais do que poderia se chamar de descentralização político-administrativa: cria-se uma nova personalidade de direito privado e transfere-se aos Coredes poderes e autonomia, inclusive financeira, se tomarmos como exemplo a decisão sobre um percentual do orçamento estadual.

Sintetizando, as principais diferenças e semelhanças entre as experiências de descentralização nos estados de Santa Catarina e do Rio Grande do Sul, evidenciadas a partir da análise da própria legislação, demonstram que, do ponto de vista da participação social, há que ser ressaltado que a legislação do RS é mais aberta e flexível, permitindo à sociedade civil organizada, por meio de seus segmentos, a inclusão de diferentes atores sociais na gestão pública. Contrariamente, a legislação catarinense é mais fechada, restringindo a participação social.

\section{REFERÊNCIAS}

ABRUCIO, F. L. Para Além da Descentralização: os desafios da coordenação federativa no Brasil. In: FLEURY, S. Democracia, Descentralização $e$ Desenvolvimento. Brasil \& Espanha. Rio de Janeiro: Editora FGV, p. 77-125, 2006.

ALLEBRANDT, S. L. Cidadania e gestão do processo de desenvolvimento: um estudo sobre a atuação dos conselhos regionais e municipais de desenvolvimento do Rio Grande do Sul, de 1990 a 2009. Santa Cruz do Sul, UNISC, 2010 (Tese de Doutorado). 
BIRKNER, W. M. K. Capital social em Santa Catarina: o caso dos fóruns de desenvolvimento regional. Blumenau: Edifurb, 2006.

BOISIER, S. Desarrollo territorial y descentralización. El desarrollo en el lugar e en las manos de la gente. Revista Eure, Santiago do Chile, n. 90, p. 27-40, set. 2004.

BRASIL. Constituição Da República Federativa do Brasil, promulgada em 5 de outubro de 1988.

BRASIL. Instituto Brasileiro de Geografia e Estatística, 2010.

COGO, E. L. Avaliação dos Processos de Descentralização nos Estados de Santa Catarina e Rio Grande do Sul: o marco jurídico como respaldo à participação social. Canoinhas (SC): Universidade do Contestado, 2011 (Dissertação defendida no Programa de Mestrado em Desenvolvimento Regional).

DALLABRIDA, V. R. (Org.). Governança Territorial e Desenvolvimento: Descentralização Político-Administrativa, Estruturas Subnacionais de Gestão do Desenvolvimento e Capacidades Estatais. Rio de Janeiro: Editora Garamond, 2011.

DALLABRIDA, V. R. A gestão territorial através do diálogo e da participação. Scripta Nova. Revista Electrónica de Geografía y Ciencias Sociales, vol. XI, núm. 245 (20), 2007.

DALLARI, D. A. Elementos de teoria geral do Estado. 25. ed. São Paulo: Saraiva, 2005.

DOWBOR, L. O que é poder local. 2. ed. São Paulo: Brasiliense, 2008 (Coleção Primeiros Passos).

FILIPPIM, E. S.; ABRUCIO, F. L. Quando descentralizar é concentrar poder: o papel do governo estadual na experiência catarinense. $R A C$, Curitiba, v.14, n. 2, p. 212-228, Mar./Abr. 2010.

MEDAUAR, O. Direito administrativo moderno. 8. ed. São Paulo: Revista dos Tribunais, 2004.

MEDICl, A. C. Economia e Financiamento do Setor Saúde no Brasil. São Paulo: Faculdade de Saúde Pública - USP, 1994.

MUÑOZ, A. E. P. Regionalização para o planejamento e o desenvolvimento do Rio Grande do Sul. Campinas, Unicamp, 2007 (Dissertação de Mestrado).

RIO GRANDE DO SUL. Lei n. 10.283, de 17 de outubro de 1994a. Dispõe sobre a criação, estruturação e funcionamento dos Conselhos Regionais de Desenvolvimento e dá outras providências, 1994a (Diário Oficial do Estado do Rio Grande do Sul n. 197). 
RIO GRANDE DO SUL. Decreto $n$. 35.764, de 28 de dezembro de 1994b. Regulamenta a Lei Estadual no 10.283/94, 1994b.

RIO GRANDE DO SUL. Constituição Estadual, promulgada a 03 de outubro de 1989.

SAAD, A. Z.; SIEDENBERG, D. R. A região do médio Alto Uruguai no Estado do Rio Grande do Sul. In: TENÓRIO, F. G. (Org.) Cidadania e desenvolvimento local. Rio de Janeiro: FGV/Ijuí: Unijuí, 2007, p. 427-488.

SANTA CATARINA. Constituição do Estado de Santa Catarina, de 5 de outubro de 1989. SANTA CATARINA. Decreto n. 2.639, de 22 de setembro de 2009d.

SANTA CATARINA. Decreto n. 2.640, de 22 de setembro de 2009c.

SANTA CATARINA. Decreto n. 2.641, de 22 de setembro de 2009b.

SANTA CATARINA. Decreto n. 2.642, de 22 de setembro de 2009a.

SANTA CATARINA. Decreto n. 2.643, de 22 de setembro de 2009.

SANTA CATARINA. Lei complementar n. 243, de 30 de janeiro de 2003.

SANTA CATARINA. Lei complementar n. 284, de 28 de fevereiro de 2005.

SANTA CATARINA. Lei complementar n. 384, de 07 de maio de 2007.

THEIS, I. M., I. M.; BUTZKE, L.; RISCHBIETER I. L. K.; LINDER, M. C.; VARGAS, D. B. O Cavalo de Troia e sua Barriga Verde: planejamento regional e desigualdades socioespaciais em Santa Catarina. Revista Paranaense de Desenvolvimento, Curitiba, n.120, p.39-56, jan./jun. 2011.

Submetido em 19/11/2012

Aprovado em 24/02/2015

Sobre os autores

Edson Luiz Cogo

Advogado e Mestre em Desenvolvimento Regional pela Universidade do Contestado (SC).

Endereço: Avenida Bernardi, 410, Cristo Redentor. 91040030 - Porto Alegre, RS - Brasil

E-mail: cogo_adv2005@yahoo.com.br

\section{Valdir Roque Dallabrida}

Geógrafo, Doutor em Desenvolvimento Regional pela Universidade de Santa Cruz do Sul (UNISC), com atuação no Mestrado em Desenvolvimento Regional da Universidade do Contestado.

Endereço: Rua Roberto Elhke, 85, Centro. 89460000 - Canoinhas, SC - Brasil

E-mail: Contato: valdirroqued897@gmail.com 